\title{
BIAS GENDER DALAM CERITA RAKYAT: (Analisis Naratif pada folklore Eropa, Cinderella, dengan Cerita Rakyat Indonesia, Bawang Merah Bawang Putih)
}

\author{
Oleh : \\ Yuliyanto Budi Setiawan, Fajriannoor Fanani, Edy Nurwahyu Julianto \\ (youlee_wazn@yahoo.co.id, carbudit@yahoo.com, glowedy@gmail.com) \\ (Tim Peneliti PKM 2013 untuk LPPM USM; Staf Pengajar Program Studi Ilmu \\ Komunikasi Universitas Semarang)
}

\begin{abstract}
:
Any interesting to compare the phenomenon of European folklore and

Indonesian folklore. This study uses narrative analysis techniques. For research purposes, such as: the gender bias describes the structure presented in the story of Indonesian folklore (Bawang Merah Bawang Putih) and European folklore (Cinderella). Then, to describe the gender bias presented in the discourse structure from the story of Indonesian folklore and European folklore. Meanwhile, the results of this study can be drawn some important points encountered in both the folklore. First, the women's attitudes are passive, forgiving, not aggressive, and accept whatever ('nrimo') is a good female figures. Second, the women's attitudes are active, ambitious, and aggressive is a bad woman figures. Third, the good woman attitudes can not changes the fate of their own, without the help of a miracle or the help of a man.
\end{abstract}

Keywords: Bias Gender, Perempuan, Bawang merah-Bawang putih

\section{Pendahuluan}

Hampir seluruh bangsa didunia ini memiliki apa yang disebut sebagai cerita rakyat. Bangsa Indonesia, karena terdiri dari berbagai suku bangsa, memiliki ratusan cerita rakyat yang beragam dan seringkali berbeda karakter. Bangsa Indonesia sementara itu juga sering mencampurkan unsur cerita rakyatnya dengan mitos dan legenda serta mengkaitkannya dengan kondisi geografis setempat. Cerita rakyat 'Asal Usul terjadinya Danau Toba' dari Sumatera Utara misalnya bercerita mengenai terbentuknya Danau Toba. Cerita 'Sangkuriang' dari Jawa Barat juga menceritakan bagaimana Gunung Tangkuban Perahu terbentuk.

Bangsa Eropa sementara itu lebih menyukai istilah folklore untuk merujuk pada cerita rakyat mereka. Akan tetapi folklore ini sendiri sebenarnya mencakup tidak hanya cerita rakyat, namun juga termasuk legenda, musik, keyakinan lokal, guyonan, dan lain-lain. Berbeda dengan cerita rakyat Indonesia, folklore bangsa Eropa tidak banyak dikaitkan dengan kondisi geografis lokal. Folklore mereka juga relatif terdokumentasi dengan baik sehingga mudah menemukan versi-versi yang baku dari setiap folklore tersebut. Folklore bangsa eropa yang terkenal misalnya adalah Cinderella, Snow White, Sleeping Beauty, Red Riding Hood, dan lain-lain.

Apapun perbedaan dari cerita rakyat bangsa Indonesia maupun folklore bangsa Eropa, keduanya sering disebut memiliki nilai-nilai moral yang berguna bagi pembentukan karakter sebuah bangsa. Sulistyarini mengatakan:

"Cerita rakyat mempunyai kedudukan dan fungsi yang sangat penting dalam masyarakat pendukungnya. Dalam cerita rakyat mengandung nilai luhur bangsa terutama nilai-nilai budi pekerti maupun 
ajaran moral. Apabila cerita rakyat itu dikaji dari sisi nilai moral, maka dapat dipilih adanya nilai moral individual, nilai moral sosial, dan nilai moral religi" (Dwi Sulistyarini, dalam http://www.adjisaka.com/ kbj5/ index. php/ 03- makalah-komisi-b/ 642-13-nilaimoral-dalam-cerita-rakyat-sebagai-saranapendidikan-budi-pekerti. Diakses pada tanggal 31 Januari 2013, pukul 8:48 WIB).

Oleh karena itu, cerita rakyat dengan demikian menjadi salah satu cara untuk memberikan pendidikan moral serta distribusi nilai-nilai bagi masyarakat. Cerita rakyat seperti 'Malin Kundang' mengajarkan untuk selalu hormat pada orang tua, 'Bawang Merah Bawang Putih' mengajarkan bahwa kebaikan pasti akan selalu menang, dan lain-lain. Hal yang sama juga ada pada folklore Eropa, 'Cinderella', 'Snow White', dan 'Sleeping Beauty' semuanya mengajarkan bahwa kebaikan pasti akan selalu menang melawan kejahatan. Cerita Rakyat, baik dari Indonesia maupun Eropa dengan demikian memiliki manfaat yang sangat positif bagi institusionalisasi nilai kebajikan pada masyarakat, terutama pada anak-anak.

Sementara itu dilain pihak, ada fenomena yang cukup menarik apabila membandingkan beberapa cerita rakyat baik dari Eropa maupun Indonesia. Apabila melihat pola cerita dari 'Cinderella', 'Sleeping Beauty', serta 'Snow White', maka bisa dilihat alur yang relatif sama dan muncul berulang-ulang. Cerita selalu dimulai dari munculnya putri yang cantik dan baik hati, lalu jatuh merana karena munculnya ibu tiri atau penyihir, dan akhirnya diselamatkan oleh pangeran tampan yang akhirnya menikahi putri cantik tersebut.

Pola yang hampir serupa juga terlihat pada cerita rakyat dari Indonesia. Apabila diambil cerita-cerita dengan tokoh utama perempuan maka terlihat pola cerita yang hampir serupa. Cerita 'Bawang Merah Bawang Putih' misalnya dimulai dari kemunculan anak perempuan yang cantik dan baik hati, lalu hidup merana karena muncul ibu tiri yang jahat, dan akhirnya mendapat keberuntungan karena memperoleh labu berisi perhiasan emas.

Kesamaan ini mungkin saja tidak berarti apa-apa, namun apabila mengacu pada studi gender hal ini dapat dipandang sebagai bagian dari institusionalisasi dari domestifikasi perempuan. Karakter wanita yang cantik, lemah, dan lembut adalah kriteria perempuan idaman yang selama ini dikritisi oleh para aktifis gender. Karakter semacam ini dianggap melemahkan wanita dan menempatkan wanita dalam posisi subordinat dan domestik. Hal ini masih diperkuat dengan peran pria dalam berbagai cerita tersebut yang digambarkan kuat, tampan, dan menjadi penyelamat perempuan. Peran pria dengan demikian adalah penyelamat kaum perempuan dan perempuan harus selalu tergantung pada kaum pria.

Berdasarkan perbandingan singkat tersebut maka terlihat bahwa Cerita Rakyat atau folklore disinyalir juga mampu ikut melestarikan dan menginstitusionalisasikan pandangan yang bias gender dalam masyarakat, terutama di Indonesia. Cerita rakyat dengan nilai-nilai yang terkandung didalamnya memiliki potensi yang besar untuk turut melakukan domestifikasi pada kaum perempuan, mendidik pasar sejak mereka masih anakanak mengenai peran perempuan dalam masyarakat yang subordinat dan selalu berada dibawah laki-laki.

Berdasarkan fenomena inilah maka kami tertarik untuk melakukan penelitian mengenai 'Bias Gender dalam Cerita Rakyat atau Folklore'. Kami tertarik untuk memahami secara lebih lanjut bagaimana bias gender tersebut hadir dalam cerita rakyat atau folklore. Kami berupaya mengkomparasi folklore 
dari Eropa dan Indonesia untuk melihat apakah dalam kedua masyarakat tersebut, yang dipisahkan oleh jarak yang sangat besar, sama-sama mengembangkan cerita rakyat yang bias gender.

Penelitian ini juga menjadi penting untuk dilaksanakan karena pemahaman yang baik mengenai bias gender dalam cerita rakyat, baik dari Eropa maupun Indonesia, akan menjadi bahan penting bagi setiap orang yang peduli akan permasalahan gender. Hasil penelitian ini dapat digunakan untuk memandang cerita rakyat dengan cara yang baru dan menggunakannya secara lebih arif.

Sementara itu, pembatasan masalah dalam studi disini dilakukan karena sebagai penelitian kualitatif maka fenomena yang diteliti memang seharusnya partikular. Begitu pula keterbatasan Peneliti secara teknis juga tidak memungkinkan untuk melakukan penelitian dalam cakupan yang lebih luas. Peneliti disini hanya meneliti satu teks folklore dari Eropa, yaitu 'Cinderella, or the Little Glass Slipper' versi dari Charles Perrault. Sementara itu, untuk cerita rakyat Indonesia kami mengambil cerita 'Bawang Merah Bawang Putih' versi dari Samsuni.

Adapun tujuan penelitiannya, antara lain: untuk mendeskripsikan bias gender dihadirkan dalam struktur cerita dari cerita rakyat Indonesia ('Bawang Merah Bawang Putih') dan folklore Eropa ('Cinderella'), serta untuk mendeskripsikan bias gender dihadirkan dalam struktur wacana dari cerita rakyat Indonesia dan folklore Eropa.

\section{Metoda}

Agar penelitian ini dapat memberikan hasil yang baik, maka penulisan laporannya menggunakan berbagai macam data, keterangan data, serta informasi penting yang diperoleh dari berbagai sumber. Untuk unit analisis dari penelitian ini adalah teks yang terdapat dalam seluruh cerita rakyat yang terpilih untuk diteliti ('Bawang Merah Bawang Putih' dan 'Cinderella').

Penelitian ini menggunakan teknik analisis naratif dari Barbatsis yang ia kembangkan dari ide Chapman. Selain itu, kami juga mengembangkan analisis Barbatsis ini dengan pemikiran lain dari Bal. Langkah-langkah dalam penelitian ini dapat dibagi menjadi beberapa tahap, antara lain:

1. Melakukan analisis pada konten/story/fabula pada dua subjek penelitian.

1.1. Melakukan analisis pada events dari konten/story/fabula pada dua subjek penelitian.

1.1.1. Melakukan analisis pada actions dari konten/story/fabula pada dua subjek penelitian.

1.1.2. Melakukan analisis pada happenings/time dari konten/story/fabula pada dua subjek penelitian.

1.2. Melakukan analisis pada existents dari konten/story/fabula pada tiga subjek penelitian.

1.2.1. Melakukan analisis pada characters/actors dari konten/story/fabula pada dua subjek penelitian.

1.2.2. Melakukan analisis pada settings/lokasi dari konten/story/fabula pada dua subjek penelitian.

2. Menganalis

wacana/diskursus/ekspresi yang terdapat pada teks cerita tiga subjek penelitian.

2.1. Mengidentifikasi dan menganalisis struktur dari transmisi naratif pada tiga subjek penelitian.

2.2. Mengidentifikasi dan menganalisis manifestasi dari cerita tersebut dalam berbagai produk budaya populer seperti film, musik, teater, dan lain-lain. Pada tahapan ini 
penelitian tidak akan khusus membandingkan subjek penelitian dengan berbagai produk budaya lain. Penelitian hanya akan membandingkan secara umum atau tidak mendetail (Barbatsis, 2005: 335

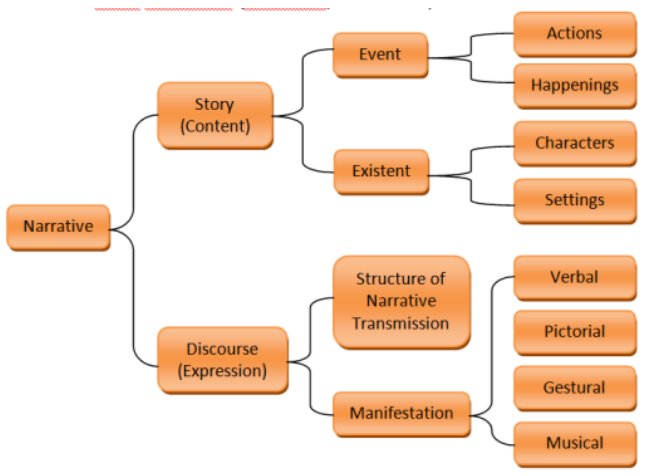

Gambar 1

Metode Analisis Naratif Barbatsis

\section{Hasil Penelitian dan Pembahasan}

A. Latar Belakang Sosio Historis

A.1. Sosio Historis Masyarakat Barat dan Peranan Wanita "Era" Cinderella

Cinderella adalah sebuah cerita rakyat yang telah berkembang di Eropa sejak zaman Yunani kuno dengan berbagai versi. Penulis yang pertama kali membuat versi yang baku mengenai Cinderella adalah Giambattista Basile yang memuat cerita Cinderella tersebut dalam buku The Pentamerone (the Story of Stories) pada tahun 1634 dengan judul Cenerentola. Cerita Cinderella dimuat kembali oleh Charles Perrault pada tahun 1697 dengan judul Histories ou Contes du Temps Passe (The Tales of Mother Goose) dengan judul The Little Glass Slipper. Pada tahun 1812 Grimm bersaudara juga menerbitkan cerita mengenai Cinderella dalam bukunya Kinder- und Hausmärchen (Grimms' Fairy Tales) dengan judul Aschenputtel.

Basile, Perrault, dan Grimm bersaudara menceritakan Cinderella menurut versi mereka masing-masing, akan tetapi versi Perrault-lah yang kemudian menjadi paling populer dan dikenal hingga kini ${ }^{1}$. Oleh karena itu, untuk memahami latar belakang sosio historis cerita Cinderella maka yang paling tepat adalah memahami latar belakang masyarakat Eropa abad ke-17, abad dimana cerita Cinderella versi Perrault diterbitkan dan menjadi populer.

Masyarakat barat pada abad ke-17 tidaklah seperti masyarakat barat yang kita kenal saat ini. Eropa pada saat itu tengah mengalami apa yang disebut sebagai era Renaissance. Pada era ini masyarakat barat tengah antusias untuk mempelajari dan mengembangkan kembali ide-ide filsafat yunani kuno. Masyarakat barat yang awalnya dikendalikan oleh dogma-dogma gereja di abad pertengahan secara tiba-tiba menemukan kebebasan dalam era renaissance. Kebebasan ini tidak hanya terjadi dalam bidang agama, namun juga menular pada bidang-bidang lain seperti politik, seni, dan sosial. Sekilas seharusnya kebebasan ini juga menjalar pada peran dan status wanita di era tersebut. Logikanya mereka seharusnya menjadi lebih bebas ketimbang pendahulu mereka di abad pertengahan, akan tetapi yang terjadi tidaklah demikian. Wanita ternyata masih sama terikatnya dengan wanita di abad pertengahan, bahkan menurut beberapa ahli mereka menjadi lebih terkungkung ketimbang generasi mereka di abad pertengahan (Harris dan Nochlind dalam http://library.thinkquest.org/C006522/life/ women.php\# diakses pada tanggal $26 \mathrm{Mei}$ 2013 pukul 21:14 dalam Women Artists, 1550-1950).

\footnotetext{
1 Cinderella versi Perrault adalah Cinderella yang kita kenal saat ini dengan ibu peri dan sepatu kacanya (lihat The Little Glass Slipper dalam The Tales of Mother Goose karangan Charles Perrault). Versi ini yang kemudian diangkat ke layar lebar oleh Disney pada tahun 1950 dengan judul Cinderella.
} 
Menurut Harris dan Nochlind hal ini dikarenakan kapitalisme yang berkembang di zaman renaissance telah membuat produksi barang menjadi semakin efektif, mengurangi peran serta, tanggung jawab, dan kontribusi ekonomi dari wanita yang sebelumnya telah mereka peroleh pada abad pertengahan.

Bagaimana wanita diperlakukan pada era renaissance ini dapat dilihat dari pernyataan Paolo da Certaldo ${ }^{2}$,

"... If you have a woman at home, keep them close to you as much as you can, and often return to the house to look after your affairs, and keep them trembling and in fear. And always make sure that they stay busy at home and that they never be idle..." (Certaldo dalam Molho, 1994: 140).

Pernyataan ini menyarankan agar wanita selalu ditempatkan dirumah, diawasi, diberi pekerjaan-pekerjaan rumah, dan bahkan selalu dibuat ketakutan. Relasi antara pria dan wanita disini tidak lebih seperti relasi antara majikan dan bawahan, karena wanita harus selalu di awasi dan dikendalikan dengan rasa takut.

Lebih lanjut ia juga mengatakan, "Do not allow furor or even anger to move you against these young men, but rather punish and admonish the girl" (Certaldo dalam Molho, 1994: 140). Menurut Molho pernyataan ini terkait dengan ketertarikan seorang pria pada wanita, saat kita menemui hal tersebut jangan memberikan hukuman pada sang pria, akan tetapi hukumlah sang wanita. Certaldo beralasan, "All great dishonori, shame, sins and expenses are incurred because of women. Because of them one acquires great enmities, and loses great friendship" (Certaldo dalam Molho, 1994: 140). Secara eksplisit dikatakan bahwa wanita adalah sumber dari segala dosa,

2 libro di buoni costume. aib, cela, dan berbagai hal buruk lainnya, karena wanita seorang pria dapat memperoleh permusuhan dan kehilangan pertemanan.

Cinderella disusun pada akhir zaman renaissance, oleh karena itu cerita tersebut kurang lebih juga disusun menurut ide-ide yang sedang berkembang pada masa tersebut. Pemahaman mengenai peran wanita yang terbatas dan terdomestifikasi pada akhirnya terefleksi dalam cerita-cerita rakyat yang berkembang pada masa itu, termasuk Cinderella.

\section{A.2. Sosio Historis Masyarakat dalam Bawang Merah Bawang Putih}

Berkebalikan dari cerita Cinderella yang dapat ditelusuri kodifikasinya dengan cukup mudah, sulit sekali menelusuri historisitas cerita Bawang Merah Bawang Putih. Sama seperti Cinderella, Bawang Merah Bawang Putih juga berasal dari cerita rakyat yang secara tradisional diceritakan dari mulut ke mulut. Sulit menemukan dokumen populer yang menulis cerita tersebut sebelum perang dunia kedua. Produk budaya pertama mengenai cerita ini malah datang dari Malaysia dengan bentuk film pada tahun 1959 berjudul Bawang Merah Bawang Putih disutradarai oleh S. Roomai Noor. Versi Samsuni yang diambil sendiri adalah versi yang dipilih karena paling mudah ditemukan dan memiliki cerita yang relatif sama dengan yang dikenal oleh banyak orang.

Sulitnya menelusuri kapan cerita ini dibuat kemudian dapat diatasi dengan mengamati setting atau latar belakang masyarakat dari cerita itu sendiri. Pada cerita tersebut keluarga Bawang Merah dan Bawang Putih digambarkan hidup di sebuah desa sederhana. Kegiatan ekonomi, rumah tangga, dan pakaian yang digunakan kemudian menunjukkan bahwa mereka hidup pada masa kira-kira era Feodal Jawa. 
Perempuan Jawa pada masa ini tidaklah sebebas sekarang. Mereka diikat oleh berbagai peraturan yang rigid mengenai tata krama dan adat istiadat. Sifat dasar masyarakat Jawa yang patriarki dengan sendirinya menempatkan perempuan dalam posisi yang subordinat atau kelas kedua setelah laki-laki. Vissia Ita Yulianto mengatakan, "seperti diketahui, perempuan pribumi telah berabad-abad menjadi babu, huishoudster atau pengatur urusan rumah tangga, istri simpanan, korban seksual, istri laki-laki Belanda." (Yulianto, 2007: 91).

Perempuan Jawa tidak hanya dijauhkan dari pendidikan, mereka dididik hanya untuk menjadi seorang istri dan seorang ibu yang baik bagi keluarga mereka. Mereka bahkan juga harus menerima saat melihat suami mereka mengambil istri kedua, ketiga, dan seterusnya. Kehidupan mereka tidak pernah lepas dari tembok rumah dan melayani para laki-laki dalam rumah tersebut. Sama halnya dengan perempuan di era Renaissance, perempuan pada zaman Feodal Jawa dengan demikian juga tersubordinasi dan hanya sekedar menjadi pelengkap dari seorang laki-laki.

Pada era orde baru, Suharto kemudian berupaya untuk mengembalikan peranan perempuan kembali di era feodal yang hanya beraktivitas di kegiatankegiatan domestik. Organisasi-organisasi perempuan yang bergerak dibidang nondomestik, seperti Gerwani, kemudian dibubarkan (Yulianto, 2007: 96). Perempuan pada era orde baru kemudian lebih banyak diarahkan pada kegiatankegiatan organisasi berorientasi domestik seperti Dharma Wanita dan PKK.

\section{B. Hasil Penelitian/Narrative dan Pembahasan}

\section{B.1. Analisis Konten (Story)}

Pada tahapan ini analisis mencoba untuk membedah cerita dari kedua subjek penelitian. Analisis ini difokuskan pada penelusuran jalan cerita, karakterisasi, hingga ke setting lokasi dan waktu dalam cerita secara literal.

\section{B.1.1. Analisis Events}

Analisis events menurut Barbatsis terbagi menjadi dua, yaitu Actions dan Happening. Actions lebih melihat dari bagaimana perkembangan cerita berjalan, sedangkan Happening melihat dari latar belakang waktu cerita tersebut berlangsung.

\section{B.1.1.1.Analisis Actions}

Cinderella dalam versi Perrault, dan versi yang paling populer, secara umum mengalami proses-proses perubahan yang signifikan. Cinderella pada awalnya adalah seorang gadis yang terhormat, cantik, dan hidup dalam lingkungan yang menyayanginya, "The gentleman had also a young daughter, of rare goodness and sweetness of temper, which she took from her mother, who was the best creature in the world".

Peruntungannya berubah saat ayahnya menikah dengan wanita lain, lingkungan yang tadinya menyayanginya menjadi sangat kejam padanya. Ibu tiri dan saudara-saudara tirinya kemudian memperlakukan dirinya seperti pembantu dirumahnya sendiri,

"The stepmother gave her the meanest work in the house to do; she had to scour the dishes, tables, etc., and to scrub the floors and clean out the bedrooms. The poor girl had to sleep in the garret, upon a wretched straw bed, ..."

Pada titik ini Cinderella juga dihadapkan pada sebuah pilihan untuk mengadukan perlakuan kasar saudara serta ibu tirinya pada sang ayah, akan tetapi ia urung melakukannya karena takut, "The poor girl bore all patiently, and dared not complain to her father, who would have scolded her if she had done so, for his wife governed him entirely"

Peruntungannya kembali berubah saat ia, dengan bantuan ibu peri, secara 
ajaib dapat mengikuti pesta dansa yang diadakan oleh pangeran kerajaan dimana ia tinggal. Dengan sepatu kaca, gaun, dan kereta kuda yang diberikan secara ajaib oleh ibu peri, Cinderella berhasil memukau para audiens dan pangeran sendiri yang sedang mencari jodoh.

"The King's son, who was told that a great princess, whom nobody knew, was come, ran out to receive her. He gave her his hand as she alighted from the coach, and led her into the hall where the company were assembled. There was at once a profound silence; every one left off dancing, and the violins ceased to play, so attracted was every one by the singular beauties of the unknown newcomer"

Pada akhirnya nasib Cinderella berubah secara drastis saat ia menikah dengan pangeran yang jatuh cinta pada dirinya. Saudara-saudaranya yang kejam pun kemudian meminta ampunan padanya

"And now her two sisters found her to be that beautiful lady they had seen at the ball. They threw themselves at her feet to beg pardon for all their ill treatment of her"

"She was conducted to the young Prince, dressed as she was. He thought her more charming than ever, and, a few days after, married her.'

Pada bagian ini Cinderella berhasil menunjukkan bahwa ia adalah putri yang dicari oleh pangeran setelah melakukan konfrontasi dengan saudara-saudaranya untuk mencoba sepatu kaca dari pangeran. Disini ia tertawa melihat saudarisaudarinya kesulitan mencoba sepatu kaca yang dibawa pangeran dan dengan menantang berkata, " Let me see if it will not fit me."

Pada kisah Cinderella tersebut dapat ditemukan tiga perubahan yang terjadi pada karakter Cinderella dan menjadi plot dari kisah tersebut. Cinderella pertama adalah gadis yang cantik dan mendapat kasih sayang, berubah menjadi gadis malang, berubah lagi menjadi gadis cantik, dan terakhir menjadi istri dari pangeran.

Sementara itu, pada cerita Bawang Merah Bawang Putih juga dapat ditelusuri plot perubahan kondisi karakter yang relatif sama. Karakter utama dalam cerita tersebut, Bawang Putih, pada awalnya adalah gadis kecil yang hidup dilingkungan keluarga sederhana namun bahagia karena disayangi oleh kedua orang tuanya,"Meskipun sang ayah hanya pedagang kecil, keluarga itu senantiasa hidup rukun, damai, dan bahagia."

Nasib buruk mulai menimpanya saat ibunya meninggal. Saat itu ada seorang janda yang berbaik hati pada keluarga tersebut dan tampak menyayangi Bawang Putih, "Mbok Randha yang sering berkunjung ke rumahnya untuk membawa makanan atau sekadar menemani Bawang Putih dan ayahnya mengobrol. Bahkan, ia kerap membantu Bawang Putih membersihkan rumah dan memasak."

Disini Bawang Putih menemui sebuah pilihan saat ayahnya bertanya pada Bawang Putih, apakah ia bersedia menerima Mbok Randha sebagai ibunya. Karena Mbok Randha saat itu baik hati maka Bawang Putih pun menerimanya,

"Bawang Putih memahami maksud ayahnya. Ia pun merasa bahwa kehadiran Mbok Randha dalam keluarganya akan membuat suasana menjadi ramai, sehingga dirinya tidak lagi kesepian. Apalagi Mbak Randha mempunyai seorang anak gadis yang bernama Bawang Merah dan sebaya dengannya. Dengan pertimbangan itu, Bawang Putih pun rela jika ayahnya menikah dengan Mbok Randha." 
Perilaku asli ibu tirinya tersebut mulai terlihat beberapa lama setelah menikah dengan ayahnya, ia dan anaknya, Bawang Merah, selalu memberikan tugas rumah yang berat pada Bawang Putih,

"setelah beberapa lama tinggal di rumah itu, sifat asli mereka yang kejam dan bengis mulai kelihatan. Ketika sang ayah sedang pergi berdagang, mereka kerap memarahi Bawang Putih dan memberinya pekerjaan berat. Bahkan, Mbok Randha tidak segan-segan menampar Bawang Putih jika sedang beristirahat barang sejenak pun untuk melepaskan lelah. Tidak hanya itu, setiap hari Bawang Putih hanya diperbolehkan makan sekali, itu pun berupa kerak nasi dengan air dan garam sebagai lauk."

Hidup Bawang Putih mulai terlihat bahagia saat ia secara tidak sengaja membantu seorang buto ijo dan dihadiahi sebuah labu kuning. Disini Bawang Putih dihadapkan pada dua buah pilihan dan karena kesederhanaanya memilih labu yang kecil, "Bawang Putih bukanlah gadis yang serakah sehingga ia hanya memilih labu yang lebih kecil."

Hidup Bawang Putih kemudian benar-benar menjadi normal kembali setelah Ibu dan Saudari tirinya tewas disengat hewan-hewan berbisa karena mengikuti langkah Bawang Putih namun memilih labu berukuran besar. Disini bawang putih mendapatkan kembali hartahartanya. "Akhirnya, Bawang Putih berhasil mendapatkan kembali semua perhiasan emas dan permatanya, kemudian menjualnya sedikit demi sedikit untuk memenuhi kebutuhan hidupnya sehari-hari."

Berdasarkan cerita tersebut dapat dilihat beberapa perubahan yang terjadi pada diri Bawang Putih. Pertama ia adalah gadis kecil sederhana yang hidup bahagia, kemudian ia menjadi gadis malang yang hidup menderita karena perlakuan ibu serta saudara tirinya, dan terakhir ia menjadi gadis yang dapat hidup normal kembali setelah kematian ibu dan saudara tirinya.

\section{B.1.1.2.Analisis Happenings/Time}

Baik cerita Cinderella dan Bawang Merah Bawang Putih memiliki durasi waktu yang relatif sama. Kedua cerita tersebut dimulai dari awal ketika mereka masih bahagia bersama ibu mereka lalu dengan agak cepat melompat ketika mereka sudah hidup menderita dengan ibu tiri mereka. Cerita inti dimulai ketika mereka sudah mengalami kesulitan dan disia-siakan oleh keluarga tiri mereka. Cerita segera berakhir ketika Cinderella menikah dengan pangeran dan keluarga tiri Bawang Putih tewas.

Berdasarkan penelitian cerita Cinderella tampaknya terjadi dalam beberapa tahun sementara action utamanya sendiri terjadi selama tiga hari. Hari pertama saat Cinderella mengikuti pesta dansa hari pertama, hari kedua saat Cinderella mengikuti pesta dansa hari kedua dan meninggalkan sepatu kacanya, dan terakhir hari ketiga saat Cinderella berhasil menemukan sepatu kacanya. Sementara itu, cerita Bawang Merah Bawang Putih juga terjadi dalam beberapa tahun sementara action utamanya terjadi dalam dua hari. Hari pertama adalah saat Bawang Putih kehilangan baju saat mencuci hingga bertemu dengan buto ijo. Hari kedua adalah saat ia membawa pulang labu berisikan perhiasan. Hari ketiga adalah saat Bawang Merah bertemu dengan Buto Ijo dan hari keempat saat Bawang Merah dan Mbok Randha tewas tersengat bisa berbagai binatang yang keluar dari labu yang mereka potong.

Sementara itu, kedua cerita juga diceritakan secara kronologis dengan alur maju tanpa flashback. Secara perlahan cerita disampaikan berurutan dengan logis dan bersambung. Latar belakang 
kehidupan dua karakter sebelum mereka mengalami penderitaan diceritakan langsung didepan, sehingga alur cerita dapat terus maju tanpa kilas balik.

\section{B.1.2. Analisis Existents \\ B.1.2.1.Analisis Characters/Actors}

Kelas dan relasi ini sendiri menurut Bal dapat dilihat dari tiga hal, antara lain:

1. Kesamaan tujuan masingmasing karakter utama.

2. Siapa saja yang memiliki kekuasaan untuk mencapai tujuan, mendorong pencapaian tujuan, atau mencegah pencapaian tujuan karakter lain.

3. Terkait dengan karakterkarakter pembantu yang bisa memberikan bantuan-bantuan pada pencapaian tujuan karakter utama (Bal, 1997: 197-201).

Berdasarkan pemahaman Bal ini maka dapat ditelusuri karakterisasi dari cerita Cinderella dan Bawang Merah Bawang Putih. Pada cerita Cinderella terdapat tiga kubu yang memiliki tujuan masing-masing. Kubu pertama adalah kubu Cinderella yang memiliki keinginan untuk hidup bahagia dan pergi ke pesta dansa. Cinderella sayangnya bukanlah karakter yang memiliki kekuasaan dan membutuhkan bantuan dari Fairy Godmother untuk mencapai tujuannya. Secara keseluruhan kedua perempuan ini juga memiliki sifat yang sama, baik hati, lembut, dan suka membantu orang lain. Secara spesifik Cinderella juga digambarkan pasif, pengalah, dan rapuh. Peran pembantu lain yang termasuk dalam kubu ini adalah ayah dari Cinderella dimana, walaupun tidak benar-benar dapat menolong Cinderella, namun ia menyayangi Cinderella dan ingin membuat Cinderella bahagia.
Sementara itu, kubu lain dari cerita ini adalah kubu Charlotte (ibu tiri Cinderella) yang termasuk didalamnya kedua saudara tiri Cinderella. Tujuan utama dari Charlotte disini adalah kebahagiaan anak-anak kandungnya dan kemudian menikahkan anak-anaknya dengan pangeran kerajaan. Dalam mencapai tujuannya tersebut Charlotte bekerja sendiri karena dialah karakter yang paling memiliki kekuasaan dalam kubunya. Tujuan dari kubu Charlotte ini sendiri harus bertentangan dengan tujuan dari kubu Cinderella, sehingga disini Charlotte banyak bertindak represif dengan menggunakan kekuasaannya untuk mencegah tujuan Cinderella tercapai. Sifat dari ketiga karakter dalam kubu ini juga hampir sama, angkuh, sombong, kejam, ambisius, dan aktif dalam mencapai keinginan mereka.

Kubu ketiga dalam cerita ini adalah kubu pangeran. Kubu ini ditandai dengan tujuan yang sama, yaitu ingin mencari pengantin bagi pangeran kerajaan, dan kemudian mencari pemilik sepatu kaca untuk dijadikan istri dari pangeran. Karakter yang termasuk dalam kubu ini antara lain pangeran dan raja. Kubu ini memiliki kekuasaan yang sangat kuat sehingga bisa mengubah peruntungan Cinderella dalam waktu yang singkat dari seorang gadis menderita menjadi seorang istri pangeran yang bahagia. Akan tetapi, walau memiliki kekuasaan yang besar, kubu ini relatif pasif dalam cerita Cinderella. Kubu ini pada akhir cerita kemudian beraliansi dengan kubu Cinderella. Sifat setiap karakter dalam kubu ini pun serupa, mereka digambarkan sebagai kaum bangsawan yang bijak, berwibawa, dan maskulin.

Sementara itu, dalam cerita Bawang Merah Bawang Putih terdapat tiga kubu dimana dua kubu pertama berseteru satu sama lain. Kubu pertama adalah kelompok Bawang Putih yang berkeinginan untuk hidup bahagia dan 
disayangi oleh setiap orang. Karakter yang termasuk dalam kelompok ini adalah Bawang Putih dan sang ayah yang berkeinginan agar Bawang Putih bahagia. Kelompok ini juga tidak memiliki kekuasaan untuk mencapai tujuannya dan seringkali dihalangi oleh kubu lain dalam mencapai tujuan. Sifat dari Bawang Putih sendiri adalah pasif, penurut, jujur, rajin, dan tidak kikir.

Kelompok lain dalam cerita ini adalah kubu dari Mbok Randha termasuk didalamnya adalah Bawang Merah. Tujuan utama dari kelompok ini adalah hidup bahagia dan memperoleh harta kekayaan yang melimpah. Kelompok ini memiliki kekuasaan dalam mencapai tujuannya dan seringkali menggunakan kekuasaannya untuk mencegah Bawang Putih mencapai tujuannya. Sifat dari kedua karakter dalam kelompok ini juga serupa, angkuh, kejam, dan kikir.

Kelompok ketiga adalah kelompok yang netral, yaitu Nini Buto Ijo. Karakter ini memiliki kekuasaan sangat besar dan dapat mengubah nasib dua kelompok lainnya. Nini Buto Ijo sendiri, walaupun digambarkan sebagai raksasa wanita, memiliki sifat yang fair.

\section{B.1.2.2.Analisis Lokasi/Settings}

Lokasi kedua cerita rakyat berlangsung dapat diidentifikasi dengan mudah melalui penceritaan yang ada. Pada cerita Cinderella lokasi cerita sebagian besar terjadi di dua tempat, rumah Cinderella dan istana kerajaan. Sementara itu, cerita Bawang Merah Bawang Putih memiliki lebih banyak setting lokasi. Cerita berlangsung di rumah Bawang Putih, sungai tempat Bawang Putih mencuci pakaian, dan terakhir di rumah Nini Buto Ijo.

\section{B.2. Analisis Wacana \\ B.2.1. Struktur Transmisi Naratif}

Struktur transmisi naratif berbicara mengenai struktur sosial yang dibangun dalam cerita tersebut. Pada analisis ini struktur sosial yang dilihat adalah bagaimana peranan wanita secara sosial dalam kedua cerita tersebut. Berdasarkan analisis konten cerita pada kedua cerita rakyat yang diteliti, maka dapat diambil beberapa premis yang sama-sama ditemui dalam kedua cerita rakyat, antara lain:

a. Perempuan yang pasif, pemaaf, tidak agresif, dan menerima apapun yang terjadi pada diri mereka (nrimo) adalah perempuan yang baik.

b. Perempuan yang aktif, ambisius, dan agresif adalah perempuan yang buruk.

c. Perempuan yang baik tidak akan dapat merubah nasib mereka sendiri tanpa bantuan keajaiban atau bantuan seorang laki-laki.

Premis yang pertama diperoleh dari deduksi bahwa kedua tokoh utama protagonis dalam kedua cerita, Cinderella dan Bawang Putih adalah perempuan yang pasif, tidak agresif, nrimo, dan pemaaf. Sementara itu, premis yang kedua diperoleh dari deduksi bahwa tokoh-tokoh antagonis dalam kedua cerita rakyat, Nyonya Charlotte, saudari-saudari tiri Cinderella, Mbok Randha, dan Bawang Merah, adalah perempuan-perempuan yang aktif, ambisius, dan agresif dalam mencapai tujuan mereka. Terakhir premis yang ketiga diperoleh dari fakta cerita bahwa baik Cinderella maupun Bawang Putih sama-sama membutuhkan bantuan keajaian untuk dapat merubah nasib mereka. Cinderella memperolehnya melalui Fairy Godmother sementara itu Bawang Putih memperolehnya melalui Nini Buto Ijo. Wacana perempuan ideal ini selanjutnya akan dibahas secara mendalam berdasarkan Muted Group Theory dalam sub bab berikutnya. 


\section{B.2.2. Manifestasi dalam berbagai budaya populer}

Pembahasan mengenai manifestasi disini terkait dengan bagaimana kedua cerita di manifestasikan dalam berbagai produk budaya. Seperti yang telah dijelaskan sebelumnya, baik Cinderella maupun Bawang Merah Bawang Putih berasal dari cerita rakyat yang berkembang dari mulut ke mulut. Model bercerita secara oral ini secara umum juga merupakan media yang umum digunakan pada setiap cerita rakyat. Model oral inilah yang kemudian memunculkan banyak versi mengenai cerita Cinderella dan Bawang Merah Bawang Putih.

Selain berbentuk cerita rakyat, kedua cerita ini juga banyak diadopsi dalam layar kaca. Versi paling terkenal dari Cinderella mungkin adalah versi yang diangkat oleh Disney dalam film tahun 1950 berjudul sama. Film ini sendiri mengacu pada versi cerita dari Charles Perrault. Sementara itu, Bawang Merah Bawang Putih juga pernah diangkat kelayar kaca sebagai film musikal di Malaysia dengan judul Bawang Putih Bawang Merah pada tahun 1959. Di Indonesia sendiri Bawang Merah Bawang Putih juga diangkat kelayar kaca sebagai sinetron dengan judul yang sama dan dibintangi oleh Revalina S. Temat dan Nia Ramadhani. Selain film layar lebar dan sinetron, cerita Cinderella dan Bawang Merah Bawang Putih juga sering diangkat dalam Direct to Video.

Berbagai jenis dan variasi versi dari cerita Cinderella dan Bawang Merah Bawang Putih ini sendiri tidaklah merubah wacana inti dari kedua cerita tersebut terkait dengan peran perempuan. Wacana inti ini adalah bahwa perempuan yang pasif adalah perempuan yang baik, perempuan yang aktif adalah perempuan yang tidak baik, dan perempuan yang baik/pasif harus memperoleh bantuan keajaiban atau laki-laki lain untuk mengubah nasib mereka. Ironisnya, cerita- cerita rakyat tersebut dikonsumsi, diterima dan dinikmati oleh apa adanya oleh siapapun (baik laki-laki maupun perempuan, baik muda maupun tua).

Sementara itu, ilustrasi sosok perempuan pasif yang diceritakan dalam Cinderella dan Bawang Merah Bawang Putih termasuk dalam kelompok terbungkam (muted group). Berdasarkan muted group theory, perempuan/kelompok terbungkam dilukiskan selalu dalam posisi kalah dan butuh pertolongan laki-laki. Selanjutnya, salah satu asumsi dasar muted group theory yaitu agar bisa berpartisipasi dan dianggap baik didalam lingkungan sosialnya, perempuan harus mengubah model ekspresi komunikasi mereka agar bisa diterima oleh sistem ekspresi dominan (laki-laki), salah satu contohnya perempuan harus mengalah dan tunduk dengan laki-laki (Ardener dalam Kramarae, 1981: 1-3).

Selain itu, adanya temuan lain yang menarik pula bahwa kedua penulis cerita Cinderella dan Bawang Merah Bawang Putih adalah laki-laki ('Cinderella, or the Little Glass Slipper' versi dari Charles Perrault, dan 'Bawang Merah Bawang Putih' versi dari Samsuni. Oleh karena itu, isi kedua cerita rakyat tersebut mengikuti perspektif/pandangan laki-laki yang berpijak pada budaya patriarkis yaitu budaya (termasuk bahasa) yang diciptakan oleh kaum laki-laki dan dilestarikan, dengan berpretensi tidak menghargai dan meniadakan kaum perempuan (dalam Griffin, 2000: 459).

Dalam ruang publik, kaum perempuan biasanya harus memiliki katakata secara baik dan cermat. Apa-apa yang hendak dikatakan oleh mereka terasa sangat sulit karena kosakata yang ada bukan diciptakan oleh mereka, tapi lebih banyak oleh kaum laki-laki. Berdasarkan teori ini juga, perempuan 'inartikulasi' karena bahasa yang mereka gunakan dibentuk dan dikembangkan secara luas oleh persepsi laki-laki tentang realitas, 
oleh karenanya perempuan 'terbungkam' (Kramarae, 1981: 1).

\section{Penutup}

Ada beberapa kesimpulan yang dapat ditarik dari hasil penelitian ini, seluruh kesimpulan tersebut terkait dengan bias gender dalam struktur cerita dan bias gender dalam struktur wacana. Bias gender dalam struktur naratif kedua cerita rakyat terlihat dari penjabaran analisis naratif yang telah dilakukan, terutama pada struktur actions dan characters kedua cerita yang diteliti, antara lain:

a. Struktur Actions, pada kedua cerita tersebut memperlihatkan perubahan nasib yang sama pada tokoh utama wanita dimana mereka dihadapkan pada pilihan yang minim dan konfrontasi yang nyaris tidak ada. Artinya semua yang terjadi pada tokoh utama wanita terjadi tanpa ia dapat kendalikan

b. Struktur Characters, pada kedua cerita tersebut menghadirkan karakterkarakter dengan sifat dan peran yang sama. Cinderella dan Bawang Putih adalah tokoh protagonis yang lemah. Mbok Randha dan Nyonya Charlotte adalah tokoh antagonis yang jahat. Saudara tiri Cinderella dan Bawang Merah adalah saudara tiri yang juga jahat. Fairy Godmother dan Nini Buto Ijo adalah karakter sihir yang bisa mengubah nasib tokoh utama.

Berdasarkan struktur cerita pada kedua cerita rakyat yang diteliti tersebut, penelitian ini bisa memperoleh struktur wacana yang dapat dirangkum dalam beberapa premis. Semua premis ini dapat ditemui dalam kedua cerita rakyat. Premis-premis tersebut, antara lain:

a. Perempuan yang pasif, pemaaf, tidak agresif, dan menerima apapun yang terjadi pada diri mereka (nrimo) adalah perempuan yang baik.

b. Perempuan yang aktif, ambisius, dan agresif adalah perempuan yang buruk.

c. Perempuan yang baik tidak akan dapat merubah nasib mereka sendiri tanpa bantuan keajaiban atau bantuan seorang laki-laki.

Premis yang pertama diperoleh dari deduksi bahwa kedua tokoh utama protagonis dalam kedua cerita, Cinderella dan Bawang Putih adalah perempuan yang pasif, tidak agresif, nrimo, dan pemaaf. Sementara itu, premis yang kedua diperoleh dari deduksi bahwa tokoh-tokoh antagonis dalam kedua cerita rakyat, Nyonya Charlotte, saudari-saudari tiri Cinderella, Mbok Randha, dan Bawang Merah, adalah perempuan-perempuan yang aktif, ambisius, dan agresif dalam mencapai tujuan mereka. Terakhir premis yang ketiga diperoleh dari fakta cerita bahwa baik Cinderella maupun Bawang Putih sama-sama membutuhkan bantuan keajaian untuk dapat merubah nasib mereka. Cinderella memperolehnya melalui Fairy Godmother sementara itu Bawang Putih memperolehnya melalui Nini Buto Ijo. Ironisnya, cerita-cerita rakyat tersebut malah dikonsumsi, diterima, dinikmati dan dilestarikan secara apa adanya oleh siapapun (baik laki-laki maupun perempuan, baik itu muda maupun tua).

\section{Daftar Rujukan}

Bal, Mieke. 1997. Narratology Introduction to the Theory of Narrative $\quad\left(2^{\text {nd }}\right)$. Toronto: University of Toronto Press. 
Griffin, E. M. 2000. A First Look at Communication Theory. USA: McGraw-Hill Companies.

Kramarae, Cherish. 1981. Women and Men Speaking, Framework for Analysis. USA: Newbury House Publishers, Inc.

Molho, Anthony. 1994. Marriage Alliance in Late Medieval Florence. Cambrige: Harvard University Press.

Vissia Ita Yulianto. 2007. Pesona 'Barat' Analisa Kritis-Historis tentang Kesadaran Warna Kulit di Indonesia. Yogyakarta: Jalasutra.

Yukawa, Joyce. 2005. Story-Lines: A Case Study of Online Learning Using Narrative Analysis: Computer Supported Collaborative Learning 2005: The Next 10 Years! New York: International Society of the Learning Sciences.
Dwi Sulistyarini. Nilai Moral dalam Cerita Rakyat sebagai Sarana Pendidikan Budi Pekerti. Dalam http://www.adjisaka.com/kbj5/inde x.php/03-makalah-komisi-b/64213-nilai-moral-dalam-ceritarakyat-sebagai-sarana-pendidikanbudi-pekerti. Diakses pada tanggal 31 Januari 2013, pukul 8:48 WIB.

Harris dan Nochlind. Dalam http://library.thinkquest.org/C0065 22/life/women.php\#. Diakses pada tanggal 26 Mei 2013 pukul 21:14 WIB dalam Women Artists, 15501950.

Samsuni. Bawang Merah Bawang Putih. Dalam http://ceritarakyatnusantara.com/id /folklore/237-Bawang-Merah-danBawang-Putih\#. Diakses pada tanggal 30 Januari 2013, pukul 11.27 WIB. 